\title{
Spatial heterogeneity and temporal dynamics of mosquito population density and community structure in Hainan Island, China
}

\author{
Yiji Li ${ }^{1,2}$, Guofa Zhou ${ }^{2}$, Saifeng Zhong ${ }^{1}$, Xiaoming Wang ${ }^{2}$, Daibin Zhong ${ }^{2}$, Elizabeth Hemming-Schroeder ${ }^{2}$, \\ Guohui $\mathrm{Yi}^{3}$, Fengyang $\mathrm{Fu}^{4}$, Faxing $\mathrm{Fu}^{1}$, Liwang Cui ${ }^{5}$, Guzhen Cui ${ }^{6,7^{*}}$ and Guiyun Yan ${ }^{2 *}$
}

\begin{abstract}
Background: Mosquitoes are vectors of many tropical diseases. Understanding the ecology of local mosquito vectors, such as species composition, distributions, population dynamics, and species diversity is important for designing the optimal strategy to control the mosquito-borne diseases.

Methods: Entomological surveillance of adult mosquitoes was conducted in five sites representing different ecological settings across Hainan Island from January to December of 2018 using BG Sentinel (BGS) traps and Centers for Disease Prevention and Control (CDC) light traps. In each site, we selected three areas representing urban, suburban and rural settings. Eighteen trap-days were sampled in each setting at each site, and CDC light traps and BGS traps were setup simultaneously. Mosquito species composition, distribution, population dynamics, and species diversity were analyzed. Mosquito densities were compared between different study sites and between different settings.

Results: Nine species of mosquitoes belonging to four genera were identified. Culex quinquefasciatus (80.8\%), Armigeres subalbatus (13.0\%) and Anopheles sinensis (3.1\%) were the top three species collected by CDC light traps; $C X$. quinquefasciatus (91.9\%), Ae. albopictus (5.1\%), and Ar. subalbatus (2.8\%) were the top three species collected by BGS traps. Predominant species varied among study sites. The population dynamics of Ae. albopictus, An. sinensis and $C X$. quinquefasciatus showed clear seasonal variation regardless of study sites with a varied peak season for different species. Mosquito abundance of all species showed significant differences among different study sites and among urban, suburban and rural areas. Danzhou had the highest mosquito biodiversity, with an $\mathrm{a}, \beta$, and Gini-Simpson biodiversity index of 8, 1.13 and 0.42 , respectively. BGS traps captured Aedes mosquito at a higher efficiency than CDC light traps, whereas CDC light traps captured significantly more Anopheles and Armigeres mosquitoes than BGS traps.

Conclusions: Mosquitoes were abundant on Hainan Island with clear seasonality and spatial heterogeneity. Population density, species composition, distribution, and species diversity were strongly affected by the natural environment. Different tools are required for the surveillance of different mosquito species.
\end{abstract}

Keywords: Hainan Island, Mosquito composition, Population dynamics, Species diversity, BGS trap, CDC light trap

*Correspondence: cuiguzhen@gmc.edu.cn; guiyuny@uci.edu

2 Program in Public Health, College of Health Sciences, University of California, Irvine, CA 92697, USA

${ }^{6}$ Key Laboratory of Medical Microbiology and Parasitology of Education

Department of Guizhou, School of Basic Medical Science, Guizhou Medical University, Guiyang, China

Full list of author information is available at the end of the article

\section{Background}

Mosquitoes transmit many diseases, such as malaria, filariasis, dengue fever, chikungunya fever, Japanese encephalitis, and yellow fever $[1,2]$. Vector control is an essential component of public health interventions to

c) The Author(s) 2020. This article is licensed under a Creative Commons Attribution 4.0 International License, which permits use, sharing, adaptation, distribution and reproduction in any medium or format, as long as you give appropriate credit to the original author(s) and the source, provide a link to the Creative Commons licence, and indicate if changes were made. The images or other third party material in this article are included in the article's Creative Commons licence, unless indicated otherwise in a credit line to the material. If material is not included in the article's Creative Commons licence and your intended use is not permitted by statutory regulation or exceeds the permitted use, you will need to obtain permission directly from the copyright holder. To view a copy of this licence, visit http://creativeco mmons.org/licenses/by/4.0/. The Creative Commons Public Domain Dedication waiver (http://creativecommons.org/publicdomain/ zero/1.0/) applies to the data made available in this article, unless otherwise stated in a credit line to the data. 
reduce the transmission of these diseases [3, 4]. Furthermore, mosquito surveillance has become increasingly important due to the continued global threat of malaria, dengue virus (DENV), Zika virus (ZIKV), chikungunya virus (CHIKV), and West Nile virus (WNV). Knowledge of mosquito population dynamics, species distribution, and species diversity is essential for developing costeffective vector surveillance tools [5]. Many factors affect mosquito population dynamics and species distribution, including climatic conditions [6], urbanization [7], and local ecological settings [8]. Mosquito population diversity and seasonal fluctuations can in turn affect the risk of mosquito-borne diseases [9]. Therefore, studies of mosquito species diversity and population dynamics can help to develop better management strategies for mosquitoborne diseases $[10,11]$. Appropriate surveillance tools for efficient mosquito population monitoring is a critical step in developing and implementing appropriate strategies to control vector populations.

Historically, mosquito-borne infectious diseases, such as malaria, dengue fever, and filariasis, have been prevalent on Hainan Island, China. For example, Hainan Island had a very severe malaria epidemic in the $1950 \mathrm{~s}$ and island-wide dengue fever pandemics in late 1970s and early 1990s [12-16]. Anopheles sinensis, Anopheles dirus, Anopheles vagus, Anopheles maculipalpis, Anopheles tessellatus and Anopheles minimus were the major malaria vectors in the past [17-19]. The 1979 and 1991 dengue fever outbreaks in Hainan, which are believed to be caused mainly by Aedes aegypti [16, 19], led to a total of 604,854 cases and 475 deaths. The most recent local dengue outbreak in Hainan occurred in 2019 [20], indicating the reemergence of the virus on the island after its cessation in 1991. While Aedes aegypti was the major dengue vector in the 1970s and 1990s [19], recent studies have shown a trend of increasing Aedes albopictus abundance and decreasing Ae. aegypti abundance since then $[21,22]$. Filariasis is also one of the historical epidemics of mosquito-borne infectious disease in Hainan till the 1980s [23]. Japanese encephalitis (JE) was used to be a major mosquito-borne infectious disease all over China including Hainan in the past, and Culex is the major vector $[24,25]$. Due to the available and widely implemented vaccination, JE has been suppressed substantially in China [24]; however, it remains a public health threat all over South, East and Southeast Asia [26]. The recent reemergence of mosquito-borne diseases, such as dengue fever, has become a new threat to public health on Hainan Island [20]. Nearly 40 species of Anopheles mosquitoes have been reported on Hainan Island in the past [19]. The dengue fever vector Ae. aegypti has also been reported [19], and Ae. albopictus, another vector of dengue fever, is widely distributed [27]. More than 18 species of Culex mosquitoes have been previously reported from Hainan Island [19]. However, no systematic mosquito surveillance has been conducted recently. Continuous monitoring of mosquito populations remains a key focus of mosquito-borne infectious disease prevention and control.

Thus, the aim of this study was to determine the mosquito population dynamics and species diversity in different ecological settings on Hainan Island. We used BGS and CDC light traps simultaneously for mosquito sampling to examine the differences in mosquito captures between the two tools and assess whether different tools are needed for mosquito population surveillance.

\section{Methods}

\section{Study areas}

Hainan Island located in the tropical area of South China Sea, with an area of $33,920 \mathrm{~km}^{2}$ and a population of 8.6 million [17]. The annual average temperature is $21.6^{\circ} \mathrm{C}$, and annual cumulative precipitation is $1980 \mathrm{~mm}$. This climate is ideal for the development and reproduction of most mosquito species [28].

Field sampling was conducted from January to December 2018 in five sites on Hainan Island, in Hainan Province, China (Fig. 1). We selected the following five locations in different geographical areas for mosquito surveillance: Haikou City, the capital of Hainan Province and the largest city in the island province; Sanya City, a major tourist destination; Wanning City; Danzhou City; and Qiongzhong City, the only mountainous site in the central area of the island (Table 1). The five sites belong to three climate zones; annual precipitation varies a lot from $1315 \mathrm{~mm}$ in Sanya to $2230 \mathrm{~mm}$ in Qiongzhong (Table 1). In addition, although there is only one rainy season in all sites, the rainy season lasts from May to October in Haikou, Sanya and Danzhou, from April to November in Qiongzhong and April to December in Wanning.

\section{Surveillance methods and sampling design}

Two types of mosquito traps were used: CDC light traps (Lucky Star Environmental Protection Technology Co., Ltd., Wuhan, China), as well as BG Sentinel trap (BioGents, Regensbourg, Germany) with BG-Lure (BioGents, $\mathrm{GmbH}$, Regensbourg, Germany).

We selected an urban, suburban, and rural area in each site for mosquito collection. The selection of the three areas at each site was to represent different ecological settings in each site and minimize differences in ecological effects. Nine traps of each of the two trap types were placed in the five study sites (Fig. 1), and sampling was carried out three to six consecutive days each month in each site. The distance between two traps was at least 40 $\mathrm{m}$. Traps were placed in randomly selected residential 
areas. The adult mosquito populations were monitored continuously from January 2018 to December 2018. CDC light traps were hung in trees $0.8 \mathrm{~m}$ above the ground, whereas BGS traps were placed on the ground. Both traps were setup in the evening, and traps were collected after $24 \mathrm{~h}$. Every $24 \mathrm{~h}$ was counted as one trapping period. Mosquitoes were collected and transported to the laboratory for species identification [29]. The geographical coordinates of each study site were recorded using eTrex $\mathrm{H}$ portable global positioning system (GPS) devices (Garmin eTrex H).

\section{Statistical analysis}

Mosquito density and comparison of differences were based on square-root transformed number of captures, as this transformation ensured overall data normality. Mosquito density was calculated as the number of mosquitoes per trap per trapping period, adults/trap-day.

For species diversity analyses, we calculated $\alpha, \beta$ and $\gamma$ diversity, as well as the Gini-Simpson diversity index based on raw records [30, 31]. $\alpha$-diversity refers to the average species diversity in a habitat or specific area, which is a local measure of diversity. $\beta$-diversity refers to the ratio between local or $\alpha$-diversity and regional diversity, i.e. the diversity of species between two habitats or regions. $\gamma$-diversity is the total diversity of a landscape and is a combination of $\alpha$ and $\beta$ diversity. True $\beta$ diversity is the Whittaker's original definitions of $\beta$-diversity [30, 31]. Absolute species turnover quantifies how much more species diversity the entire dataset contains than an average subunit within the dataset. This can also be interpreted as the total amount of species turnover among the subunits in the dataset [32]. The Gini-Simpson index accounts for how individuals are distributed among species in different study sites [33]. The formula for the GiniSimpson index is $G=1-\sum_{i=1, n} p_{i}^{2}$, where $p_{i}$ is the proportion of species $i$ in a given study site.

Differences in monthly average of mosquito abundance (time series) among different study sites were tested using one-way analysis of variance (ANOVA) with repeated measures after data transformation. Pairwise differences in mosquito abundance were determined using the ANOVA Tukey-Kramer HSD post-hoc test with a significance level of 0.05 . Statistical analysis was carried out using JMP 9.0 statistical software (JMP, SAS Institute Inc., Cary, NC, USA).

A generalized linear mixed model (GLMM) with Poisson error and log link function was used to analyze the effects of trap configurations and study sites on the numbers of mosquitoes collected based on raw numbers [34]. The data used for GLMM analysis was pooled data of all mosquito species for each genus. To test for study site effects, sampling months were used as covariates. To compare differences in trapping methods, both

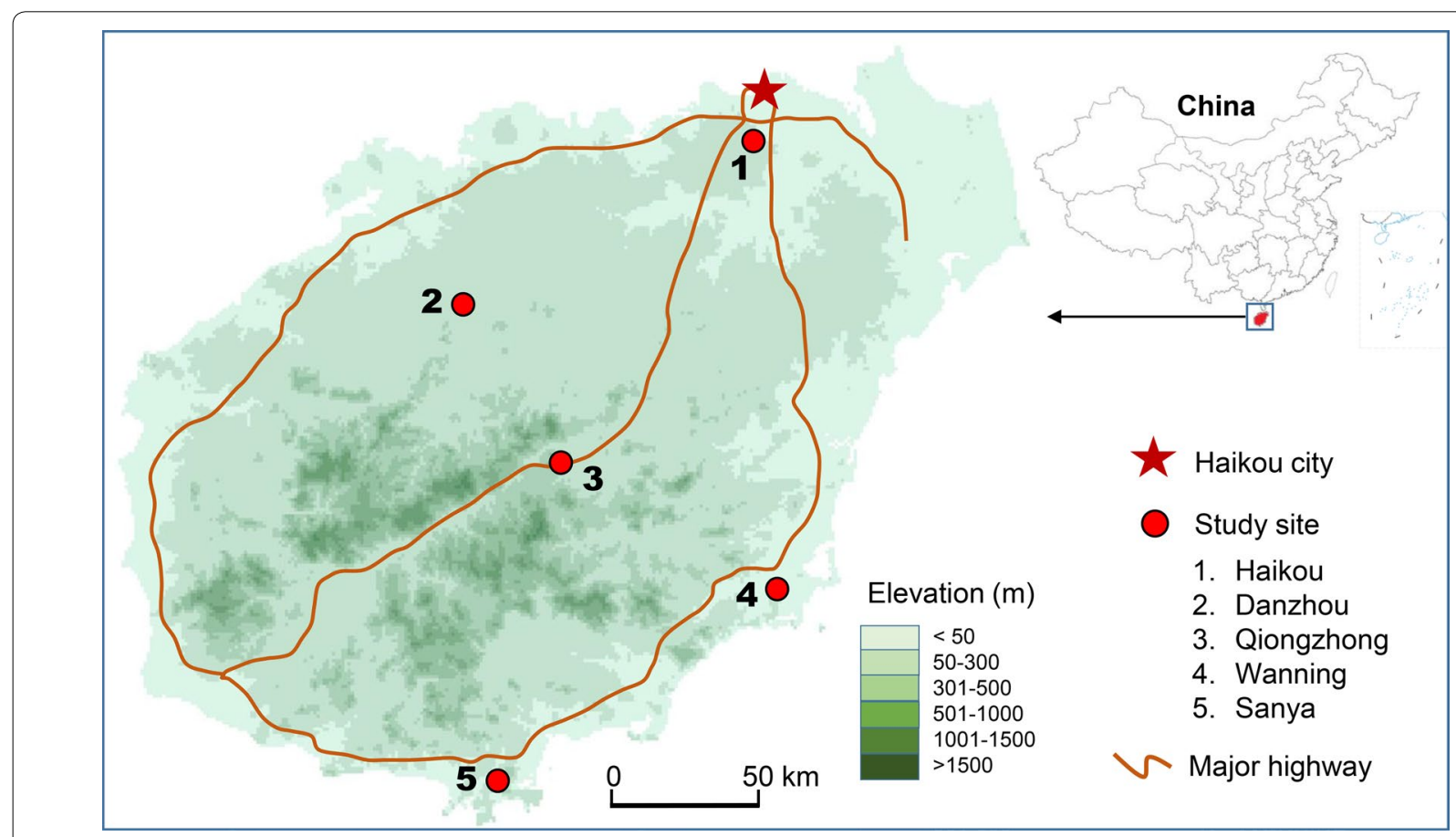

Fig. 1 Map of the study sites in Hainan Island, China 
Table 1 Description of study sites in Hainan Island, China

\begin{tabular}{lllllll}
\hline Study site & Location & $\begin{array}{l}\text { Elevation } \\
(\mathrm{m} \text {.a.s.I. })\end{array}$ & Landscape & Climate zone & $\begin{array}{c}\text { Annual mean } \\
\text { temperature }\left({ }^{\circ} \mathrm{C}\right)\end{array}$ & $\begin{array}{c}\text { Annual } \\
\text { precipitation } \\
(\mathrm{mm})\end{array}$ \\
\hline Haikou & $110^{\circ} 19^{\prime} \mathrm{E}, 19^{\circ} 59^{\prime} \mathrm{N}$ & 25 & Highly urbanized & Humid subtropical & 24.2 & 1650 \\
Danzhou & $109^{\circ} 35^{\prime} \mathrm{E}, 19^{\circ} 30^{\prime} \mathrm{N}$ & 46 & Plain, agriculture & Tropical humid monsoon & 23.8 & 1830 \\
Qiongzhong & $109^{\circ} 50^{\prime} \mathrm{E}, 19^{\circ} \mathrm{O} 2^{\prime} \mathrm{N}$ & 213 & Mountain, forest & Tropical marine monsoon & 23.1 & 2230 \\
Wanning & $110^{\circ} 22^{\prime} \mathrm{E}, 18^{\circ} 48^{\prime} \mathrm{N}$ & 10 & Mountain and plain & Tropical savanna & 25.0 & 2040 \\
Sanya & $109^{\circ} 32^{\prime} \mathrm{E}, 18^{\circ} 19^{\prime} \mathrm{N}$ & 8 & Major tourist place & Tropical savanna & 25.9 & 1315 \\
\hline
\end{tabular}

Abbreviation: m.a.s.l., meters above sea level

study sites and sampling months were used as covariates. In addition, a temporal correlation effect was modelled using AR (1) correlation structure. GLMM analysis was performed using R 3.6.3.

\section{Results}

\section{Mosquito population composition}

A total of 1505 and 1337 trap-days of CDC light trap and BGS trap were conducted during the survey period. Using CDC light traps, we collected a total of 44,778 mosquitoes belonging to four genera and at least nine species (Table 2). Among the CDC light trap catches, 36,159 were $C x$. quinquefasciatus, 5835 Armigeres subalbatus, 1380 An. sinensis, 696 Ae. albopictus, 449 Cx. tritaeniorhynchus, and others (An. vagus, Cx. bitaeniorhynchus, An. aconitus and An. hyrcanus group) (Table 2). Culex quinquefasciatus (80.8\%), Armigeres subalbatus (13.0\%) and $A n$. sinensis (3.1\%) were the top three species collected by CDC light traps. Using BGS traps, we collected a total of 43,387 mosquitoes belonging to four genera and at least five species (Table 1). Among them, 39,889 were Cx. quinquefasciatus, 2208 Ae. albopictus, 1214 Ar. subalbatus, 70 An. sinensis, and others (Cx. tritaeniorhynchus and Cx. bitaeniorhynchus) (Table 2). Culex quinquefasciatus (91.9\%), Ae. albopictus (5.1\%) and Ar. subalbatus (2.8\%) were the top three species collected by BGS traps. No Ae. aegypti were collected during the study period.

For CDC light traps, among all study sites, Danzhou had the highest density of Culex (52.55 \pm 10.13 adults/ trap-day), Anopheles (4.37 \pm 0.84 adults/trap-day) and Armigeres (14.53 \pm 2.57 adults/trap-day) mosquitoes (Tukey-Kramer HSD all $P<0.05$ ) (Table 3). Danzhou and Sanya had the highest density of Aedes mosquitoes, with $0.76 \pm 0.11$ and $0.76 \pm 0.15$ adults/trap-days, respectively (Tukey-Kramer HSD both $P<0.05$ ) (Table 3). For BGS traps, Haikou had the highest Aedes mosquito density (2.51 \pm 0.43 adults/trap-day) (Tukey-Kramer HSD $P<$ 0.05); Wanning had the highest density of Culex mosquitoes (49.08 \pm 9.18 adults/trap-day) (Tukey-Kramer HSD $P<0.05)$; and Danzhou had the highest density of
Anopheles ( $0.26 \pm 0.08$ adults/trap-day) and Armigeres $(3.70 \pm 0.57$ adults/trap-day) mosquitoes (Tukey-Kramer HSD both $P<0.05$ ) (Table 3).

\section{Population dynamics of the predominant species}

Here we focused on four major species, i.e. Cx. quinquefasciatus, Ae. albopictus, Ar. subalbatus and An. sinensis. Figure 2 shows the population dynamics of these four species at our study sites by different trapping methods. The population dynamics of $C x$. quinquefasciatus showed clear seasonal variation regardless of study sites and trapping methods, although some sites showed a low density overall (Fig. 2a). The peak months were in general from March to May (Fig. 2a). The population dynamics of Ae. albopictus captured by BGS traps showed significant seasonal changes, with a peak collection likely between March and October of the year. CDC light trap collections showed significantly lower density overall, as compared to BGS traps, but CDC light traps revealed a slight peak of Ae. albopictus from April to July (Fig. 2b). For both Ar. subalbatus and An. sinensis, BGS was not an effective surveillance tool (with very few adults captured) and showed minimal seasonal variation in comparison to $\mathrm{CDC}$ light traps (Fig. 2c, d). For both species, CDC light trap catches showed a strong seasonality with peak collection from April to September for Ar. subalbatus and from April to August for An. sinensis (Fig. 2c, d).

\section{Mosquito species diversity}

For this analysis, data were pooled for each study site. In total, nine species (genera) were collected (Table 4). At the species level, Haikou had the lowest $\alpha$ diversity (6 species) and lowest Gini-Simpson diversity index (0.17), while Danzhou had the highest $\alpha$ diversity (8 species) and Gini-Simpson diversity index (0.42). Species turnover was low (from 0 to 2 ) for all paired-sites (Table 4). Overall, in consideration of the number of individuals captured, species diversity was generally 
Table 2 Descriptive summary of trap data by mosquito species

\begin{tabular}{lll}
\hline Species & CDC light trap & BGS trap \\
\hline Number of trap days & 1505 & 1337 \\
Anopheles sinensis & $1380(3.1)$ & $70(0.2)$ \\
Anopheles vagus & $89(0.2)$ & 0 \\
Anopheles aconitus & $4(<0.1)$ & 0 \\
Anopheles hyrcanus group & $3(<0.1)$ & 0 \\
Aedes albopictus & $696(1.6)$ & $2208(5.1)$ \\
Culex quinquefasciatus & $36159(80.8)$ & $39889(91.9)$ \\
Culex tritaeniorhynchus & $449(1.0)$ & $6(<0.1)$ \\
Culex bitaeniorhynchus & $163(0.4)$ & 0 \\
Armigeres subalbatus & $5835(13.0)$ & $1214(2.8)$ \\
Total number & $44778(100)$ & $43387(100)$ \\
\hline
\end{tabular}

Notes: Data represent total number of mosquitoes (percentage of total)

low, as the average Gini-Simpson index was 0.14 and ranged from 0.07 in Wanning to 0.42 in Danzhou (Table 4).

The impact of study areas, urbanized setting, and trapping methods on mosquito abundance

Overall, all Aedes, Culex, Anopheles and Armigeres population densities were significantly different among trapping methods and study sites (all $P<0.001$, Table 5). Poisson regression analyses showed that CDC light traps had a lower efficiency than BGS traps in capturing Aedes and Culex mosquitoes $(Z=-29.9, P<$ 0.001 for Aedes; $Z=-32.4, P<0.001$ for Culex). However, CDC light traps had a higher efficiency in capturing Anopheles and Armigeres mosquitoes $(Z=20.9, P<$ 0.001 for Anopheles; $Z=40.4, P<0.001$ for Armigeres).

Aedes was the only species that did not show significant differences in densities among months, and Anopheles was the only species that did not show significant interactions among trapping methods, study sites and study areas. (Table 5)

Data were pooled from different sites for analyzing differences in mosquito abundance among urban, suburban and rural areas. Mean mosquito abundance showed strong differences among urban, suburban and rural areas (Fig. 3). For both Aedes and Culex mosquitoes, the abundance was lowest in suburban areas, whereas, population abundance for both genera were similar in rural and urban areas (Fig. 3a, b). Over 95\% of Anopheles mosquitoes were found in rural areas, and about $80 \%$ of Armigeres were collected from rural areas. Both mosquito genera showed no difference in abundance between urban and suburban areas (Fig. 3c, d). Poisson regression analysis showed significant differences in mosquito abundances among collection
Table 3 Mean mosquito density by study site and mosquito genus

\begin{tabular}{|c|c|c|c|c|c|}
\hline Site & $n$ & Aedes & Culex & Anopheles & Armigeres \\
\hline \multicolumn{6}{|l|}{ BGS trap } \\
\hline Haikou & 297 & $2.51 \pm 0.43$ & $\begin{array}{c}25.73 \pm \\
2.48\end{array}$ & 0 & $0.14 \pm 0.03$ \\
\hline Danzhou & 209 & $1.13 \pm 0.14$ & $\begin{array}{c}25.54 \pm \\
2.81\end{array}$ & $0.26 \pm 0.08$ & $3.70 \pm 0.57$ \\
\hline $\begin{array}{l}\text { Qiong- } \\
\text { zhong }\end{array}$ & 179 & $0.39 \pm 0.07$ & $\begin{array}{c}14.15 \pm \\
1.78\end{array}$ & $0.04 \pm 0.02$ & $0.58 \pm 0.11$ \\
\hline Sanya & 240 & $1.64 \pm 0.22$ & $\begin{array}{c}17.34 \pm \\
2.32\end{array}$ & $0.03 \pm 0.01$ & $0.56 \pm 0.10$ \\
\hline Wanning & 412 & $1.85 \pm 0.20$ & $\begin{array}{c}49.08 \pm \\
9.18\end{array}$ & 0 & $0.07 \pm 0.02$ \\
\hline \multicolumn{6}{|c|}{ CDC light trap } \\
\hline Haikou & 323 & $0.43 \pm 0.09$ & $9.85 \pm 0.85$ & $0.08 \pm 0.02$ & $0.49 \pm 0.09$ \\
\hline Danzhou & 260 & $0.76 \pm 0.11$ & $\begin{array}{c}52.55 \pm \\
10.13\end{array}$ & $4.37 \pm 0.84$ & $14.53 \pm 2.57$ \\
\hline $\begin{array}{l}\text { Qiong- } \\
\text { zhong }\end{array}$ & 234 & $0.26 \pm 0.05$ & $\begin{array}{c}14.37 \pm \\
1.89\end{array}$ & $0.75 \pm 0.14$ & $2.86 \pm 0.37$ \\
\hline Sanya & 275 & $0.76 \pm 0.15$ & $7.32 \pm 0.50$ & $0.24 \pm 0.04$ & $3.09 \pm 0.41$ \\
\hline Wanning & 413 & $0.20 \pm 0.02$ & $\begin{array}{c}35.26 \pm \\
3.47\end{array}$ & $0.17 \pm 0.05$ & $0.83 \pm 0.10$ \\
\hline
\end{tabular}

Abbreviation: $n$, number of collections

areas for all mosquitoes after adjustments for sampling months, sampling methods and study sites (Table 5).

\section{Discussion}

Hainan Island has a tropical climate and complex terrain. It has been reported that there are many mosquito species distributed across the island in the past [21, 35]. In our study, we found that there are at least nine mosquito species present on Hainan Island. Anopheles, Aedes, Culex and Armigeres mosquitoes, which are found on the island, are important vectors of mosquitoborne diseases, such as malaria, dengue, filariasis, zika, chikungunya. Armigeres subalbatus is the vector of the zoophilic Wuchereria bancrofti, which causes filariasis in humans [36]. In our study, An. sinensis, Cx. quinquefasciatus, Ae. albopictus and Ar. subalbatus were found to be widely distributed across the island and occurring at high densities. We also found $C x$. quinquefasciatus, Ar. subalbatus and Ae. albopictus year round. The presence of these species throughout the year can be explained by the tropical climate on the island with plenty of year-round rainfall, and thus breeding habitats are widely available and perennial. Malaria, dengue fever and other mosquito-borne tropical diseases were all prevalent on the island in the recent past $[15,20]$. Therefore, vector surveillance is important for the control and prevention of mosquito-borne diseases. 
CDC Light Trap
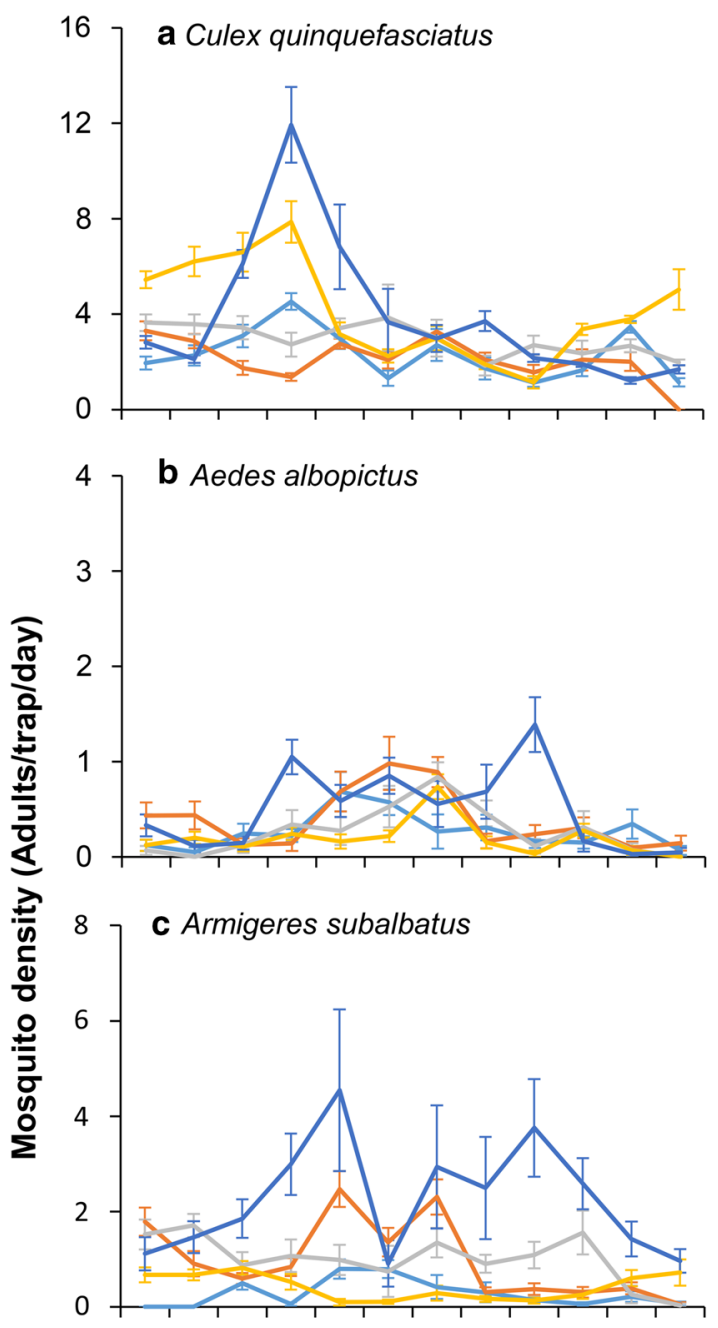

4 d Anopheles sinensis

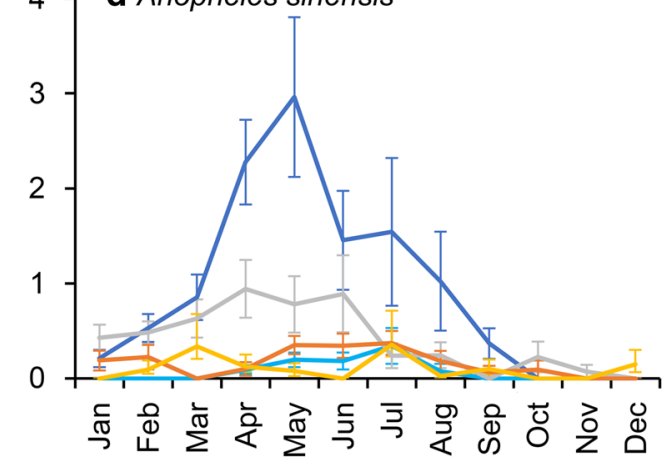

Month
BG Sentinel Trap
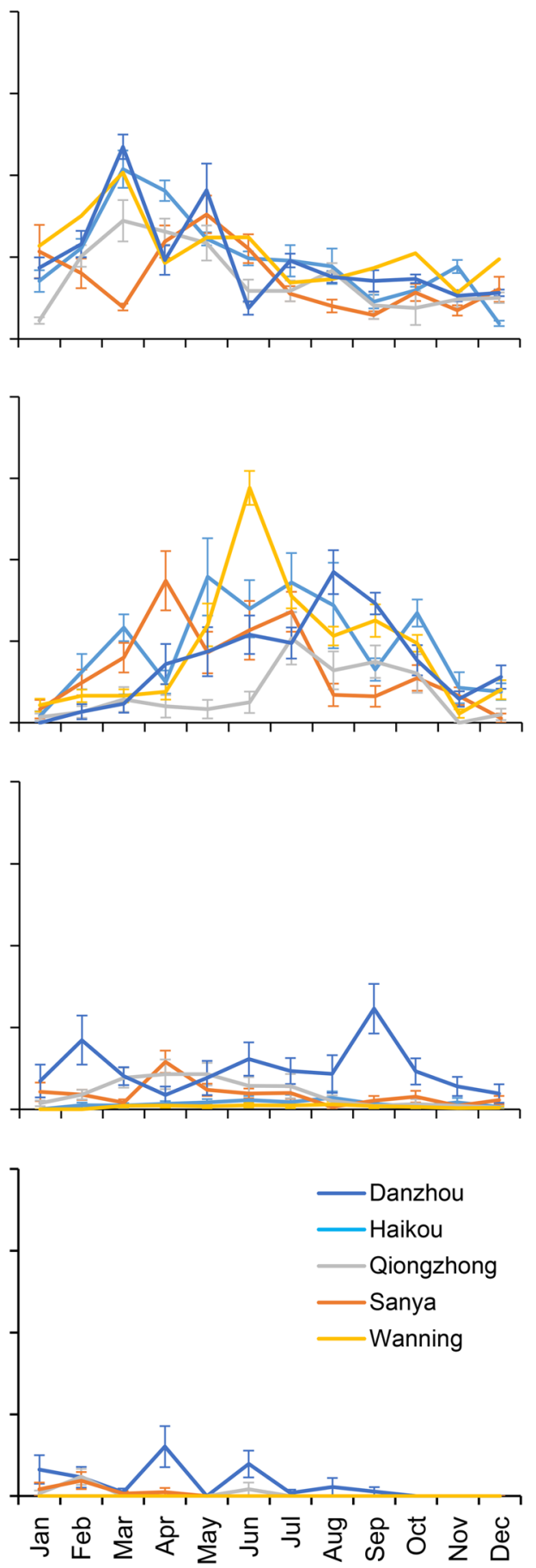

\section{Month}

Fig. 2 Dynamics of major mosquito species in Hainan Island, China 2018. a Culex quinquefasciatus. b Aedes albopictus. c Armigeres subalbatus. d Anopheles sinensis. The left panels show mosquito captures by CDC light trap, the right panels show mosquito captures by BG Sentinel Trap. Mosquito abundance is square-root transformed, and values are the mean \pm standard error 
Table 4 Species and individual level diversity analysis by location

\begin{tabular}{|c|c|c|c|c|c|c|}
\hline Study areas & Haikou & Qiongzhong & Danzhou & Wanning & Sanya & Total \\
\hline \multicolumn{7}{|l|}{ Species level } \\
\hline$\gamma$ diversity (overall) & & & & & & 9 \\
\hline a diversity (species richness) & 6 & 8 & 8 & 7 & 7 & 9 \\
\hline True $\beta$ diversity & 1.50 & 1.13 & 1.13 & 1.29 & 1.29 & - \\
\hline Proportional species turnover $\beta_{p}$ & 0.33 & 0.11 & 0.11 & 0.22 & 0.22 & - \\
\hline \multicolumn{7}{|l|}{ Individual level } \\
\hline Gini-Simpson biodiversity index & 0.17 & 0.31 & 0.42 & 0.07 & 0.38 & 0.14 \\
\hline
\end{tabular}

Notes: Diversity measure types: a denotes the diversity within a study site, higher values mean higher diversity; $\beta$ denotes differences in diversity between samples from a study site and the overall, a value of 1 means that the study site has all the species found in all study sites; $\gamma$ denotes the total diversity over the set of all samples; $\beta_{p}$ represents the proportional difference between overall diversity and the diversity in specific study site

We found strong heterogeneity in mosquito population distributions, as mosquito density of all genera, Anopheles, Aedes, Culex and Armigeres, varied significantly among the five study sites, which is likely a reflection of differences in ecological settings. Different ecological conditions, urban residential, suburban mixed residential and agricultural, and rural agricultural areas, also impacted the distribution and density of mosquito species, a finding which is consistent with previous studies [37-39]. For example, rural areas had a significantly higher density of Anopheles and Armigeres mosquitoes than that in urban and suburban areas. Thus, optimal surveillance and mosquito control strategies may be required in different places, so as to adapt to the local mosquito distribution and dynamics in different areas.

Furthermore, Ae. albopictus survive in the tropical Hainan Island throughout the year, and the peak season has expanded to April-October in 2018. The peak season in Hainan Island is longer than the average peak season of Ae. abopictus in north and central China, which is June-September [40]. The tropical climate of Hainan Island is likely more suitable for the survival of Ae. abopictus, and thus Hainan Island may be at a higher risk of future dengue outbreaks. Previous studies in Guangzhou and other places showed that urban areas had a higher proportion of container type habitats, whereas more agricultural related habitats are found in the rural area. These two habitat types support the breeding of different mosquito species [37, 41], which may in part explain the difference in species composition in these areas. However, there is no detailed habitat availability evidence from Hainan Island, so further studies are needed.

There were differences in mosquito catches between CDC light traps and BGS traps. In our study, CDC light traps captured nine species of mosquitoes, whereas BGS traps only captured five species. However, the two methods may be complementary and thus, used in
Table 5 Poisson regression analysis of differences in mosquito density for each genus. Intercept terms are not shown

\begin{tabular}{|c|c|c|c|c|}
\hline Genus & & $d f$ & $x^{2}$ & $P$ \\
\hline \multirow[t]{8}{*}{ Aedes } & Month & 1 & 0.96 & 0.3268 \\
\hline & Method & 1 & 1031.13 & $<0.00001$ \\
\hline & Site & 4 & 349.92 & $<0.00001$ \\
\hline & Area & 2 & 292.31 & $<0.00001$ \\
\hline & Method*Site & 4 & 241.29 & $<0.00001$ \\
\hline & Method*Area & 2 & 6.12 & 0.0470 \\
\hline & Site ${ }^{*}$ Area & 8 & 178.76 & $<0.00001$ \\
\hline & Method*Site*Area & 8 & 198.67 & $<0.00001$ \\
\hline \multirow[t]{8}{*}{ Culex } & Month & 1 & 21955.76 & $<0.00001$ \\
\hline & Method & 1 & 1076.99 & $<0.00001$ \\
\hline & Site & 4 & 18709.47 & $<0.00001$ \\
\hline & Area & 2 & 5157.04 & $<0.00001$ \\
\hline & Method*Site & 4 & 4894.59 & $<0.00001$ \\
\hline & Method*Area & 2 & 2298.21 & $<0.00001$ \\
\hline & Site ${ }^{*}$ Area & 8 & 22579.33 & $<0.00001$ \\
\hline & Method*Site*Area & 8 & 3164.88 & $<0.00001$ \\
\hline \multirow[t]{8}{*}{ Anopheles } & Month & 1 & 333.49 & $<0.00001$ \\
\hline & Method & 1 & 1370.70 & $<0.00001$ \\
\hline & Site & 4 & 2810.98 & $<0.00001$ \\
\hline & Area & 2 & 2312.00 & $<0.00001$ \\
\hline & Method*Site & 2 & 17.23 & 0.0002 \\
\hline & Method*Area & 1 & 4.16 & 0.0413 \\
\hline & Site ${ }^{*}$ rea & 7 & 164.47 & $<0.00001$ \\
\hline & Method*Site*Area & 2 & 1.76 & 0.4139 \\
\hline \multirow[t]{8}{*}{ Armigeres } & Month & 1 & 372.03 & $<0.00001$ \\
\hline & Method & 1 & 2955.65 & $<0.00001$ \\
\hline & Site & 4 & 9305.74 & $<0.00001$ \\
\hline & Area & 2 & 4761.00 & $<0.00001$ \\
\hline & Method*Site & 4 & 74.95 & $<0.00001$ \\
\hline & Method*Area & 2 & 727.38 & $<0.00001$ \\
\hline & Site ${ }^{*}$ Area & 7 & 154.47 & $<0.00001$ \\
\hline & Method*Site*Area & 2 & 1250.70 & $<0.00001$ \\
\hline
\end{tabular}

Notes: Method: CDC light trap and BGS trap; Site: Haikou, Sanya, Wanning, Danzhou and Qiongzhong; Area: urban, suburban and rural

Abbreviation: $d f$, degrees of freedom 



Fig. 3 Mosquito densities in different urbanized setting. a Aedes. b Culex. c Anopheles. d Armigeres. Values are the mean \pm standard error. Bars labelled with different letters within the same panel are significantly different from each other $(P<0.05)$

conjunction with each other for population monitoring, as they work differently on certain genera. For example, CDC light traps captured Anopheles and Armigeres mosquitoes more effectively, while BGS traps captured Aedes mosquitoes at a higher rate, which is consistent with previous studies $[3,42,43]$. The two tools work equally well in capturing Culex mosquitoes. While CDC light traps captured more species overall, the two methods complement each other by their differential effectiveness at capturing mosquito genera. There are also many other mosquito sampling methods, such as human landing catch (HLC), animal-baited traps, landing boxes, pit shelters, etc. $[44,45]$. Each sampling method may be suitable for different mosquito species. For example, zoophilic mosquitoes such as Anopheles arabiensis are more attracted to cattle than humans, so a cattle-baited trap is a potentially more effective method for sampling this species than human landing catches [46]. Each trapping method has its advantages and disadvantages, which have been reported in detail by Lima et al. [47] and Killeen et al. [48]. The effectiveness of other sampling methods in our study area require further study.
Interestingly, in our study, we did not find any $A e$. aegypti. Aedes aegypti used to be the dominant Aedes species on Hainan Island and was responsible for dengue fever pandemics on the island from 1970s-1990s [19]. Aedes aegypti was last reported on the island in 2012 from a few isolated places [21]. Aedes albopictus has been reported throughout the island in the past few years [21, 22]. Whether the disappearance of Ae. aegypti in Hainan is the result of replacement by Ae. albopictus is worthy of further investigation. If there is a species replacement, questions related to how species replacement occurs and how species replacement affects dengue virus transmission require further investigation.

Armigeres (Armigeres) subalbatus is a species complex of zoophilic mosquitoes belonging to the genus Armigeres, which is the least studied genus of mosquitoes captured during this study with regard to public health [36, $49,50]$. It is a natural vector for filarial worms of livestock, which causes filariasis in humans $[36,50]$. This species has also been found at a low density and carrying virus in Yunnan, China [50]. Moreover, a study in central China found that Ar. subalbatus mosquitoes may 
carry many different viruses [51]. Indeed, Ar. subalbatus has been confirmed as a vector of many virus [52]. In this study, we found a high density (compared to Aedes and Anopheles) of mosquitoes belonging to the Ar. subalbatus complex year-round, which may have public health implications given the vector potential of this complex. However, limited by the study aims, we did not test the infection status of all mosquitoes, but this line of inquiry may be worthy of further investigations.

In our study, we only collected nine species of mosquitoes on Hainan Island in 2018, which is a substantially lower number than collected in previous studies in Hainan [53]. One of the reasons for this discrepancy is likely due to the trapping locations. In this study, we mainly placed mosquito traps near residential areas. However, some mosquito species, such as An. dirus and An. minimus are known to inhabit mountainous areas with forest or forest edges [54]. Both An. dirus and An. minimus are malaria vectors which were present on the island in the past [28], but they may have been simply missed by our experimental designs. Secondly, Hainan Island is experiencing rapid development, urbanization, road construction and other developments, which may have caused environmental modifications that in turn affect larval habitability and mosquito survival of some species. Many studies have demonstrated that changes in the landscape can affect the distribution of the local mosquito vectors [55-57]. Future sampling should cover more diverse ecological settings, so that results can reflect the true species diversity of the mosquito community.

\section{Conclusions}

We carried a year-long, multi-site mosquito population dynamics study in Hainan, China. The results indicated that BGS traps and CDC light traps complement each other for surveillance of different mosquito vectors. Additionally, mosquito density, population dynamics and diversity showed strong spatial heterogeneity. Therefore, different intervention strategies may be required in different geographical regions and land use types, in order to achieve robust and cost-effective vector surveillance and control for reducing mosquito-borne disease risk.

\section{Abbreviations \\ DF: dengue fever; ZIKV: Zika virus; CHIKV: chikungunya virus; WNV: West Nile virus; JE: Japanese encephalitis; BGS trap: BG sentinel trap; CDC light trap: Centers for Disease Control and Prevention light trap.}

\section{Acknowledgements}

We wish to thank Hao Chen, Xiaojia Chen, Shihao Han, Ziqi He, Weiwei Meng, Mingfa Li, Yusheng Zhong, and Gan Yu, who assisted with the field trap surveillance.

\section{Authors' contributions}

YL, GC and GY designed the study. YL, SZ, XW, EHS, DZ, GY, FYF and FXF performed the field and laboratory work. YL, LC and GZ analyzed and processed data. YL, GZ and GY wrote the manuscript with assistance from EHS and GC. All authors read and approved the final manuscript.

\section{Funding}

This study was supported by the National Natural Science Foundation of China (81660345 and 31760318), the Talent Introduction Fund of Hainan Medical University (2016011), the Guizhou Science and Technology Foundation ([2019]1441, [2018]1132 and [2018]5779-17), China Scholarship Council fellowship (201808460069), and the National Institutes of Health of the US (U19 Al089672 and U19 Al129326).

\section{Availability of data and materials}

All data generated or analysed during this study are included in this published article.

\section{Ethics approval and consent to participate}

Not applicable.

\section{Consent for publication \\ Not applicable.}

\section{Competing interests}

The authors declare that they have no competing interests.

\section{Author details}

${ }^{1}$ Department of Pathogen Biology, Hainan Medical University, Haikou, Hainan, China. ${ }^{2}$ Program in Public Health, College of Health Sciences, University of California, Irvine, CA 92697, USA. ${ }^{3}$ Public Research Laboratory, Hainan Medical University, Haikou, Hainan, China. ${ }^{4}$ Department of Medical Technology, Chongqing Medical and Pharmaceutical College, Chongqing, China. ${ }^{5}$ Department of Internal Medicine, Morsani College of Medicine, University of South Florida, Tampa, FL 33612, USA. ${ }^{6}$ Key Laboratory of Medical Microbiology and Parasitology of Education Department of Guizhou, School of Basic Medical Science, Guizhou Medical University, Guiyang, China. ${ }^{7}$ Key Laboratory of Endemic and Ethnic Diseases Ministry of Education, Guiyang, China.

Received: 10 June 2020 Accepted: 30 August 2020

Published online: 04 September 2020

References

1. Lee H, Halverson S, Ezinwa N. Mosquito-borne diseases. Prim Care. 2018;45:393-407

2. Tolle MA. Mosquito-borne diseases. Curr Probl Pediatr Adolesc Health Care. 2009;39:97-140.

3. Li Y, Su X, Zhou G, Zhang H, Puthiyakunnon S, Shuai S, et al. Comparative evaluation of the efficiency of the BG-Sentinel trap, CDC light trap and mosquito-oviposition trap for the surveillance of vector mosquitoes. Parasit Vectors. 2016:9:446.

4. Morrison AC, Zielinski-Gutierrez E, Scott TW, Rosenberg R. Defining challenges and proposing solutions for control of the virus vector Aedes aegypti. PLoS Med. 2008;5:e68.

5. Wang Y, Zhong D, Cui L, Lee M, Yang Z, Yan G, et al. Population dynamics and community structure of Anopheles mosquitoes along the ChinaMyanmar border. Parasit Vectors. 2015:8:445.

6. Biteye B, Fall AG, Ciss M, Seck MT, Apolloni A, Fall M, et al. Ecological distribution and population dynamics of Rift Valley fever virus mosquito vectors (Diptera, Culicidae) in Senegal. Parasit Vectors. 2018;11:27.

7. Montagner FRG, Silva OS, Jahnke SM. Mosquito species occurrence in association with landscape composition in green urban areas. Braz J Biol. 2018;78:233-9.

8. Chaverri LG, Dillenbeck C, Lewis D, Rivera C, Romero LM, Chaves LF. Mosquito species (Diptera: Culicidae) diversity from ovitraps in a mesoamerican tropical rainforest. J Med Entomol. 2018;55:646-53.

9. Mwangangi JM, Midega J, Kahindi S, Njoroge L, Nzovu J, Githure J, et al. Mosquito species abundance and diversity in Malindi, Kenya and 
their potential implication in pathogen transmission. Parasitol Res. 2012;110:61-71.

10. Mwangangi JM, Mbogo CM, Orindi BO, Muturi EJ, Midega JT, Nzovu $J$, et al. Shifts in malaria vector species composition and transmission dynamics along the Kenyan coast over the past 20 years. Malar J. 2013;12:13.

11. LaDeau SL, Leisnham PT, Biehler D, Bodner D. Higher mosquito production in low-income neighborhoods of Baltimore and Washington, DC: understanding ecological drivers and mosquito-borne disease risk in temperate cities. Int J Environ Res Public Health. 2013;10:1505-26.

12. Chen W, Wu K, Lin M, Li C. Great achievements of anti-malaria for a half century and the present technical problems in Hainan Island. Chin Trop Med. 2007:07:2013-6.

13. Wang S, Cai X. The prevalence of malaria in Hainan Province and its control. Chinese J Pest Control. 1996;1 1996(Suppl. 1):23-7.

14. Huan J, Wang S, Lin S. Analysis of results of malarial control, monitoring and infections in Hainan Province from 2000 to 2008. Chin Trop Med. 2010;2:146-8.

15. Hu X, Zeng W, Wang S, Wang G, Meng F, Li Y. Analysis of malaria surveillance in monitoring sites of Hainan Province from 2006 to 2010. Chin Trop Med. 2013;01:46-9.

16. Jin Y, Sun L, Zeng X, Wu W, Ma Y, Su X, et al. Seroepidemiological survey of dengue fever in Hainan Province from 2005 to 2006. Chin Trop Med. 2007;11:2007-8

17. Riley WA. Anopheline mosquitoes from the Island of Hainan, China. Lingnan Sci J. 1932;11:468.

18. Zhang S, Guo S, Feng X, Afelt A, Frutos R, Zhou S, et al. Anopheles vectors in mainland China while approaching malaria elimination. Trends Parasitol. 2017;33:889-900.

19. Wei S, Lin S, Yang C. The 50-year history of the development of health in Hainan Province. Haikou: Southern Press; 2007. p. 396-7.

20. The People's Government of Hainan Province. http://www.hnntv.cn/st/ jrrd/2019-09-10/350737.html. Accessed 10 Sep 2019.

21. He C, Zhao W, Wang S, Zeng L, Li S, Ou T. Analysis of mosquito density and seasonality in urban areas of Hainan province, China in 2012. Chin J Vector Biol Control. 2014;25:15-7.

22. Su A, Pei Z, Fu J, Li J, Feng F, Zhu Q, et al. Analysis of distribution and population density changes of Aedes egypti the transmission vector of dengue fever in Haikou City. Chin Trop Med. 2005;06:1394-5.

23. Wu R, Xu F, Xin F, Liu Z. History of investigation, prevention and research of filariasis in Hainan Province. Chin Trop Med. 2003;01:33-7.

24. Zheng Y, Li M, Wang H, Liang G. Japanese encephalitis and Japanese encephalitis virus in mainland China. Rev Med Virol. 2012;22:301-22.

25. Wang J, Pan X, Zhang H, Fu S, Wang H, Tang Q, et al. Japanese encephalitis viruses from bats in Yunnan, China. Emerg Infect Dis. 2009;15:939-42.

26. WHO. Japanese encephalitis. Geneva: World Health Organization; 2020. https://www.who.int/ith/diseases/japanese_encephalitis/en/

27. Wang Z, Wang S, Xiaoye Y, Gaomu ZY, Fu JTL, Zeng L, et al. Investigaton on Ae. aegypti and Ae. albopictus in the north-western part of Hainan Province. Chin Trop Med. 2005;02:230-3.

28. Qin Q, Li Y, Zhong D, Zhou N, Chang X, Li C, et al. Insecticide resistance of Anopheles sinensis and An. vagus in Hainan Island, a malaria-endemic area of China. Parasit Vectors. 2014;7:92.

29. Dong X, Zhou H, Gong Z. The mosquito fauna of Yunnan. 1st ed. Yunnan: Yunnan Science \& Technology Press; 2010.

30. Veech JA, Summerville KS, Crist TO, Gering JC. The additive partitioning of species diversity: recent revival of an old idea. Oikos. 2002;99:3-9.

31. Lande R. Statistics and partitioning of species diversity, and similarity among multiple communities. Oikos. 1996;76:5-13.

32. Tuomisto $\mathrm{H}$. A diversity of beta diversities: straightening up a concept gone awry. Part 1. Defining beta diversity as a function of alpha and gamma diversity. Ecography. 2010;33:2-22.

33. Sahney S, Benton MJ, Ferry PA. Links between global taxonomic diversity, ecological diversity and the expansion of vertebrates on land. Biol Lett. 2010;6:544-7.

34. Derua YA, Kahindi SC, Mosha FW, Kweka EJ, Atieli HE, Wang XM, et al. Microbial larvicides for mosquito control: impact of long-lasting formulations of Bacillus thuringiensis var. israelensis and Bacillus sphaericus on nontarget organisms in western Kenya highlands. Ecol Evol. 2018;8:7563-73.
35. Sun D, Wang G, Zeng L, Li S, He C, Hu X, et al. Extensive resistance of Anopheles sinensis to insecticides in malaria-endemic areas of Hainan Province, China. Am J Trop Med Hyg. 2017;97:295-8.

36. Muslim A, Fong MY, Mahmud R, Lau YL, Sivanandam S. Armigeres subalbatus incriminated as a vector of zoonotic Brugia pahangi filariasis in suburban Kuala Lumpur, Peninsular Malaysia. Parasit Vectors. 2013;6:219.

37. Li Y, Kamara F, Zhou G, Puthiyakunnon S, Li C, Liu Y, et al. Urbanization increases Aedes albopictus larval habitats and accelerates mosquito development and survivorship. PLoS Negl Trop Dis. 2014;8:e3301.

38. Zahouli JBZ, Koudou BG, Müller P, Malone D, Tano Y, Utzinger J. Urbanization is a main driver for the larval ecology of Aedes mosquitoes in arbovirus-endemic settings in south-eastern Côte d'Ivoire. PLoS Negl Trop Dis. 2017;11:e0005751.

39. Zahouli JBZ, Koudou BG, Müller P, Malone D, Tano Y, Utzinger J. Effect of land-use changes on the abundance, distribution, and host-seeking behavior of Aedes arbovirus vectors in oil palm-dominated landscapes, southeastern Côte d'Ivoire. PLoS One. 2017;12:e0189082.

40. Yan D, Gao Y, Wu H, Wang Y, Zhao N, Zhu C, Zhang Q, Wang J, Liu Q. An analysis of surveillance data of Aedes albopictus in 21 provinces, China, 2016. Chin J Vector Biol Control. 2019;30:391-4.

41. Wang $Y$, Cheng $P$, Jiao $B$, Song $X$, Wang $H$, Wang $H$, et al. Investigation of mosquito larval habitats and insecticide resistance in an area with a high incidence of mosquito-borne diseases in Jining, Shandong Province. PLoS One. 2020;15:e229764.

42. Unlu I, Baker M. Comparison of BG-sentinel prototype, BG-sentinel-1, and BG-sentinel-2: better results with modification of earlier design. J Am Mosq Control Assoc. 2018;34:237-9.

43. Arimoto H, Harwood JF, Nunn PJ, Richardson AG, Gordon S, Obenauer PJ. Comparison of trapping performance between the original BGsentinel ${ }^{\circledR}$ Trap and BG-sentinel $2^{\circledR}$ trap (1). J Am Mosq Control Assoc. 2015;31:384-7.

44. Sikulu M, Govella NJ, Ogoma SB, Mpangile J, Kambi SH, Kannady K, et al. Comparative evaluation of the Ifakara tent trap-B, the standardized resting boxes and the human landing catch for sampling malaria vectors and other mosquitoes in urban Dar es Salaam, Tanzania. Malar J. 2009;8:197.

45. Wong J, Bayoh N, Olang G, Killeen GF, Hamel MJ, Vulule JM, et al. Standardizing operational vector sampling techniques for measuring malaria transmission intensity: evaluation of six mosquito collection methods in western Kenya. Malar J. 2013;12:143.

46. Asale A, Duchateau L, Devleesschauwer B, Huisman G, Yewhalaw D. Zooprophylaxis as a control strategy for malaria caused by the vector Anopheles arabiensis (Diptera: Culicidae): a systematic review. Infect Dis Poverty. 2017;6:160

47. Lima JB, Rosa-Freitas MG, Rodovalho CM, Santos F, Lourenço-de-Oliveira R. Is there an efficient trap or collection method for sampling Anopheles darlingi and other malaria vectors that can describe the essential parameters affecting transmission dynamics as effectively as human landing catches? - A review. Mem Inst Oswaldo Cruz. 2014;109:685-705.

48. Killeen GF, Tatarsky A, Diabate A, Chaccour CJ, Marshall JM, Okumu FO, et al. Developing an expanded vector control toolbox for malaria elimination. BMJ Global Health. 2017;2:e000211.

49. Suman DS. Efficacy of diurnal BG-sentinel traps to capture nocturnal adult Armigeres subalbatus mosquitoes and impact of altitudinal variations in forests. Asian Pac J Trop Med. 2019;12:512.

50. Zhang $\mathrm{H}$, Zhang Y, Yang W, Feng Y, Nasci RS, Yang J, et al. Mosquitoes of western Yunnan Province, China: seasonal abundance, diversity, and arbovirus associations. PLoS One. 2013;8:e77017.

51. Xia H, Wang Y, Shi C, Atoni E, Zhao L, Yuan Z. Comparative metagenomic profiling of viromes associated with four common mosquito species in China. Virol Sin. 2018;33:59-66.

52. Liang G, Li X, Gao X, Fu S, Wang H, Li M, et al. Arboviruses and their related infections in China: a comprehensive field and laboratory investigation over the last 3 decades. Rev Med Virol. 2018;28:e1959.

53. Sun D, Wang S, Zeng L, Li S, Zhuo K. Survey of the diversity of Anopheles species in Hainan province. J Pathog Biol. 2014;9:271-4.

54. Kar NP, Kumar A, Singh OP, Carlton JM, Nanda N. A review of malaria transmission dynamics in forest ecosystems. Parasit Vectors. 2014;7:265.

55. Chaves LF, Friberg MD, Jian JY, Moji K. Landscape and environmental factors influencing stage persistence and abundance of the bamboo mosquito, Tripteroides bambusa (Diptera: Culicidae), across an altitudinal gradient. Insects. 2019;10:41. 
56. Trewin BJ, Pagendam DE, Zalucki MP, Darbro JM, Devine GJ, Jansen CC, et al. Urban landscape features influence the movement and distribution of the Australian container-inhabiting mosquito vectors Aedes aegypti (Diptera: Culicidae) and Aedes notoscriptus (Diptera: Culicidae). J Med Entomol. 2020;57:443-53.

57. Zittra C, Vitecek S, Obwaller AG, Rossiter H, Eigner B, Zechmeister T, et al. Landscape structure affects distribution of potential disease vectors (Diptera: Culicidae). Parasit Vectors. 2017;10:205.

\section{Publisher's Note}

Springer Nature remains neutral with regard to jurisdictional claims in published maps and institutional affiliations.
Ready to submit your research? Choose BMC and benefit from:

- fast, convenient online submission

- thorough peer review by experienced researchers in your field

- rapid publication on acceptance

- support for research data, including large and complex data types

- gold Open Access which fosters wider collaboration and increased citations

- maximum visibility for your research: over $100 \mathrm{M}$ website views per year

At BMC, research is always in progress.

Learn more biomedcentral.com/submissions 